\title{
Model Hubungan Waktu Terjadinya Tumpahan Minyak di Suatu Lokasi dengan Bentuk Sebarannya pada Daerah Terdampak Studi Kasus: Tumpahan Minyak di Sekitar Pesisir Lhokseumawe-NAD
}

\section{A Relationship Model Between an Occurrence of Oil Spill and its Spread Around an Impacted Area Case Study: Oil Spills on a Coastal Area of the Lhokseumawe-NAD}

\author{
NAWA SUWEDI \\ Pusat Teknologi Lingkungan, Badan Pengkajian dan Penerapan Teknologi \\ Gedung Geostek 820, Kawasan Puspiptek, Serpong, Tangerang Selatan 15314 \\ nawa.suwedi@bppt.go.id
}

\begin{abstract}
The rising of offshore oil, gas exploration, and exploitation activities conducted in a coastal area potentially lead to oil spills. The oil spill occurrence in the coastal area of the Lhokseumawe-NAD can possibly pose a threat to the national marine park conservation and also destroy the beauty of a beach environment surrounding of the Weh Island. In order to reduce the threat, utilization of an oil spill model can increase the capabilities on early oil spill handling and tackling. The oil spill model has capabilities to simulate a minimum drifting time and a spreading of the oil in the Lhokseumawe coastal area. According to the simulation results, the oil spill occurrence in the Lhokseumawe coastal area on January, February, June, July, August, September, October, November, or December could reach a coastal area of the Weh Island with a minimum drifting time about 24 -288 hours and depends on daily wind and current conditions. On March, the oil spreading will not exactly reach the Weh Island's beach, instead, it will tend to spread to the north part of Weh Island. Meanwhile, on April or May the oil spill spreading is estimated to will never reach the beach of Weh Island.
\end{abstract}

Keywords: Oil spill, minimim drifting time, oil spreading, Lhokseumawe, model

\begin{abstract}
ABSTRAK
Maraknya kegiatan eksplorasi dan ekploatasi minyak dan gas bumi yang dilakukan di lepas pantai Lhokseumawe-NAD berpotensi menimbulkan terjadinya tumpahan minyak yang secara langsung juga berpotensi mengancam kelestarian taman laut nasional dan keindahan lingkungan pantai yang ada di sekitar Pulau Weh. Sebagai upaya untuk mengurangi ancaman tersebut, model Oil Spill dapat digunakan untuk membantu meningkatkan kemampuan dalam penanganan dan penanggulangan tumpahan minyak secara dini. Model Oil Spill mempunyai kemampuan untuk mensimulasikan minimum drifting time dan pola sebaran tumpahan minyak yang ada di sekitar perairan Lhokseumawe. Berdasarkan hasil simulasi, pada bulan Januari, Pebruari, Juni, Juli, Agustus, September, Oktober, Nopember, atau Desember tumpahan minyak yang terjadi di sekitar perairan Lhokseumawe akan sampai ke Pulau Weh dengan Minimum drifting time berkisar antara 24 jam - 288 jam dan bergantung pada kondisi angin dan arus harian. Pada bulan Maret sebaran tumpahan minyak tidak mencapai pantai Pulau Weh tetapi menyebar cenderung ke sebelah utara Pulau Weh. Pada bulan April atau Mei sebaran tumpahan minyak tidak pernah sampai ke Pulau Weh.
\end{abstract}

Kata Kunci: Tumpahan minyak, minimim drifting time, sebaran tumpahan minyak, Lhokseumawe, model

\section{PENDAHULUAN}

Maraknya kegiatan eksplorasi dan ekploatasi minyak dan gas bumi yang dilakukan di lepas pantai Lhokseumawe berpotensi menimbulkan terjadinya tumpahan minyak yang dapat mengancam kelestarian dan keindahan lingkungan laut dan pantai yang ada di sekitar Pulau Weh. Pulau Weh atau sering juga disebut dengan Pulau We atau Pulau Sabang merupakan salah satu daerah tujuan wisata alam di Provinsi Nangro Aceh Darussalam (NAD). Jumlah wisatawan, baik wisatawan lokal maupun wisatawan asing ${ }^{(1)}$, yang datang ke Pulau Weh dari tahun ke tahun mengalami peningkatan. Maraknya wisatawan yang datang tidak lepas dari kondisi lingkungan alam yang indah dan terdapatnya berbagai objek wisata alam yang menarik. Obyek wisata alam 
tersebut antara lain adalah Pantai Ibioh (yang berjarak sekitar $6 \mathrm{~km}$ dari Tugu KM-0) dan taman laut nasional yang ada di sekitar pulau Rubiah. Pulau Weh dengan luas luas wilayah sekitar 122,14 $\mathrm{Km}^{2}$ merupakan bagian dari wilayah administrasi Kota Sabang ${ }^{(2)}$

Kegiatan eksplorasi dan eksploatasi minyak di lepas pantai yang berpotensi menimbulkan terjadinya tumpahan minyak antara lain adalah: kegiatan pemboran sumur uji dan sumur produksi, operasionalisasi sumur minyak, kegiatan pemipaan bawah laut, dan transportasi kapal pengangkut minyak, serta lalu lalang kapal yang mendukung kegiatan eksplorasi dan produksi minyak dan gas bumi.

Minyak yang tumpah ke laut dapat dalam wujud tersebar di permukaan (surface spreading), teruapkan (evaporation), teremulsi (emulsification), terpecah (dissolution), terdegradasi secara biologi (biodegradation), terdispersi (dispersion), dan tersedimentasi (sedimentation), advection, turbulent diffusion ${ }^{(3)}$

Selain itu minyak yang tumpah ada kemungkinan terjadi interaksi minyak dengan pantai, mengalami variasi temporal terhadap viskositas, densitas, dan tegangan permukaan ${ }^{(4)}$.

Sebaran tumpahan minyak dipengaruhi oleh berbagai faktor, antara lain: angin dan arus yang terjadi di sekitar lokasi tumpahan minyak $^{(4,5,6)}$, jumlah minyak, karakteristik minyak, dan pasang surut ${ }^{7,8,9)}$. Tumpahan minyak ini dapat tersebar dalam bentuk lapisan minyak ataupun emulsi ${ }^{(6)}$. Minyak yang telah tersebar (yang sudah pindah dari lokasi awalnya) dapat mengalami hal yang sama seperti minyak ketika tumpah di lokasi awalnya.

Tumpahan minyak ke laut juga berpotensi menimbulkan dampak negatif terhadap flora dan fauna yang ada di dalamnya. Sebaran minyak yang mencapai terumbu karang dapat mengganggu kelangsungan hidup terumbu karang $^{(10)}$, sebaran tumpahan minyak yang sampai ke wilayah hutan mangrove akan berpengaruh pada kehidupan hutan mangrove dan menggangu proses pemijahan berbagai jenis binatang laut yang ada di hutan mangrove tersebut, tumpahan minyak yang telah mencemari ikan dapat mempengaruhi kesehatan manusia ${ }^{(11)}$.

Sebaran tumpahan minyak, selain mengakibatkan pada permasalahan lingkungan juga dapat mengakibatkan pada permasalahan sosial dan ekonomi pada daerah yang dilaluinya. Lingkungan yang tercemar oleh tumpahan minyak, kualitasnya menjadi turun. Turunnya kualitas lingkungan berpengaruh dengan terhadap kesejahteraan masyarakat yang ada di sekitarnya ${ }^{(12)}$. Apabila semua resiko penanggulangan dan pemulihan kualitas lingkungan akibat terjadinya tumpahan minyak jadi beban negara maka efek timbulnya kerugian negara dan pembengkakan pengeluaran negara menjadi bertambah ${ }^{(13)}$

Kecepatan dan keberhasilan penanganan tumpahan minyak sangat tergantung pada: kemampuan teknologi, ketersediaan, jumlah, kecepatan, dan keberadaan kapal, serta kesiapsiagaan personel pelaksana penanganan tumpahan minyak. Adapun peralatan yang digukan untuk mengatasi terjadinya tumpahan minyak antara lain adalah oil booms dan/atau oil skimmers ${ }^{(14)}$

Memperhatikan dampak negatif yang ditimbulkan ini, terjadinya tumpahan minyak dari kegiatan eksplorasi dan eksploatasi minyak dan gas yang ada di lepas pantai Lhokseumawe-NAD perlu diwaspadai. Peningkatan kewaspadaan menjadi penting karena proses penanganan tumpahan minyak di laut ternyata tidak mudah. Dalam rangka peningkatan kewaspadaan tersebut maka diperlukanlah model yang dapat digunakan untuk membantu proses penanganan dan penanggulangan tumpahan minyak secara dini. Tujuan penelitian ini diarahkan untuk mengetahui waktu minimum yang diperlukan oleh tumpahan minyak agar sampai ke perairan di sekitar Pulau Weh dan pola sebaran tumpahan minyak yang sampai di pantai atau perairan di sekitar Pulau Weh.

\section{BAHAN DAN METODE}

Dalam penelitian ini data yang digunakan untuk mensimulasikan kasus ini adalah: data kondisi angin di sekitar lokasi tumpahan minyak dan data properties minyak itu sendiri. Sedangkan lokasi tumpahan minyak diasumsikan terjadi di koordinat $97^{\circ} 16^{\prime} 30^{\prime \prime}$ BT dan $05^{\circ} 16^{\prime} 30^{\prime \prime} \mathrm{LU}$, yaitu di perairan laut di sebelah utara Lhokseumawe-NAD. Data angin yang digunakan untuk simulasi model ini diambil dari Stasiun Meteorologi Lhokseumawe yaitu antara Januari 2006 sampai Desember $2010^{(15}$. Jumlah minyak yang tumpah diasumsikan sebesar 6 ton/jam dengan properties minyak yang digunakan dalam simulasi dapat dilihat pada Tabel 1.

Tablel 1. Properties dari minyak yang digunakan untuk simulasi

\begin{tabular}{lc}
\hline Properties & Quantities \\
\hline Density $\left(\mathrm{kg} / \mathrm{m}^{3}\right)$ & 825 \\
Viskosity $(\mathrm{cP})$ & 10.0 \\
Pour Point $\left({ }^{\circ} \mathrm{C}\right)$ & -19 \\
Flash Point $\left({ }^{\circ} \mathrm{C}\right)$ & 5.5 \\
\hline
\end{tabular}

Simulasi model sebaran tumpahan minyak dilakukan dengan menggunakan software OilSpil for Windows versi 3.0 yang ada di Seawatch Indonesia. Data dan hasil dari model tumpahan minyak yang digunakan dapat 
digambarkan sebagaimana yang dapat dilihat di Gambar1. Sedangkan untuk melihat arah angin dominan per-bulan selama periode 2006-2010 yang terdapat di sekitar perairan Lhokseumawe digunakan software Windrose ${ }^{(16)}$.

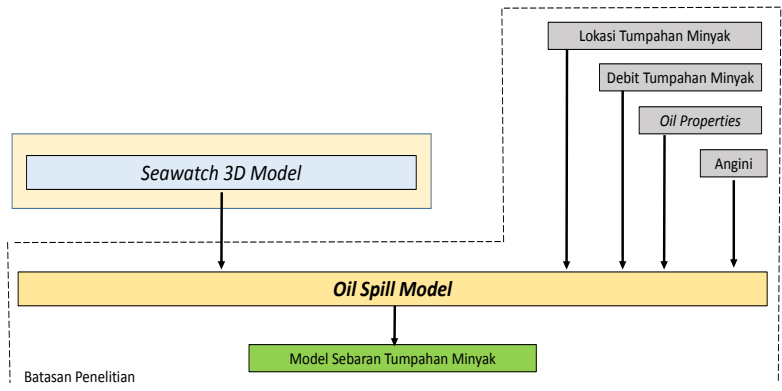

Gambar 1. Input-output Model Tumpahan Minyak

\section{HASIL DAN PEMBAHASAN}

Hasil pengolahan data angin tiap bulan dari bulan Januari 2006 sampai Desember 2010 dapat dilihat pada Gambar 2 (bulan Januari Juni) dan Gambar 3 (Juli - Desember). Dari Gambar 2 dan Gambar 3, dapat dilihat adanya pola sebaran angin yang berbeda untuk bulan yang berbeda yang sangat berpengaruh terhadap pola sebaran tumpahan minyak pada bulan-bulan yang berbeda. Distribusi arah angin pada masing-masing bulan adalah:

- bulan Januari, cenderung menyebar menuju ke arah Barat sampai Timur Laut dengan arah angin dominan menuju Timur Laut,

- bulan Pebruari, cenderung menyebar menuju ke arah Barat sampai Timur Laut dengan arah angin dominan menuju Barat Laut,

- bulan Maret, cenderung menyebar menuju ke arah Barat sampai Timur Laut dengan arah angin dominan menuju Barat Laut,

- bulan April, cenderung menyebar menuju ke arah Barat sampai Barat Laut dengan arah angin dominan menuju Barat Laut,

- bulan Mei, cenderung menyebar menuju ke arah Barat sampai Barat Laut dengan arah angin dominan menuju Barat Laut,

- bulan Juni, cenderung menyebar menuju ke arah Selatan sampai Barat Laut dengan arah angin dominan menuju Selatan,

- bulan Juli, cenderung menyebar menuju ke arah Selatan sampai Barat dengan arah angin dominan menuju Selatan,

- bulan Agustus, distribusi arah angin cenderung menyebar menuju ke arah Selatan sampai Timur Laut dengan arah angin dominan menuju Barat,

- bulan September, cenderung menyebar menuju ke arah Barat sampai Timur Laut dengan arah angin dominan menuju Barat,

- bulan Oktober, cenderung menyebar menuju ke arah Barat sampai Tmur Laut dengan arah angin dominan menuju Barat Laut,

- bulan Nopember, cenderung menyebar menuju ke arah Barat sampai Tmur Laut dengan arah angin dominan menuju Timur Laut,

- bulan Desember, cenderung menyebar menuju ke arah Selatan sampai Barat Laut dengan arah angin dominan menuju Barat. 


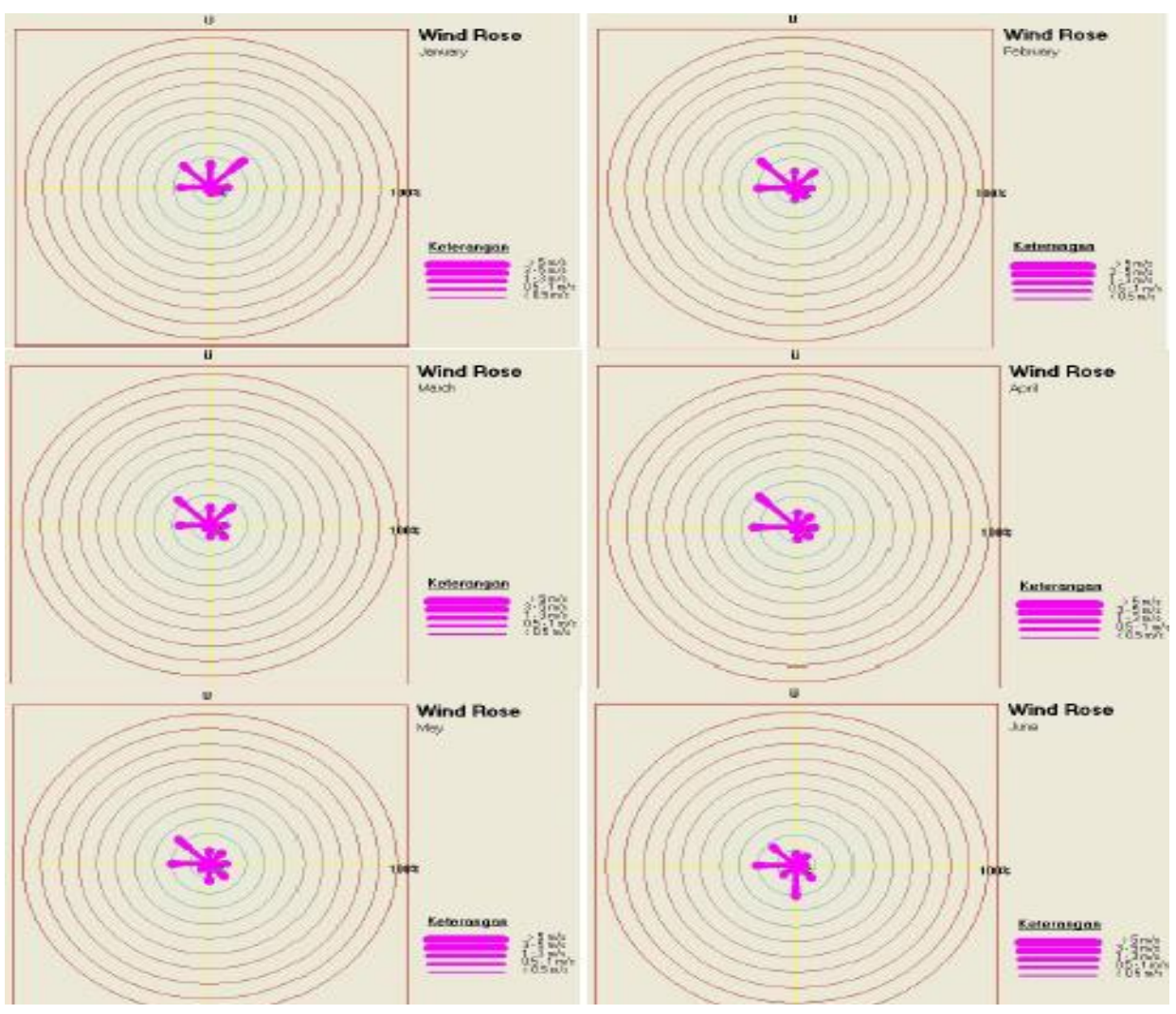

Gambar 2. Windrose data angin bulan Januari - Juni dari data tahun 2006 - 2010.

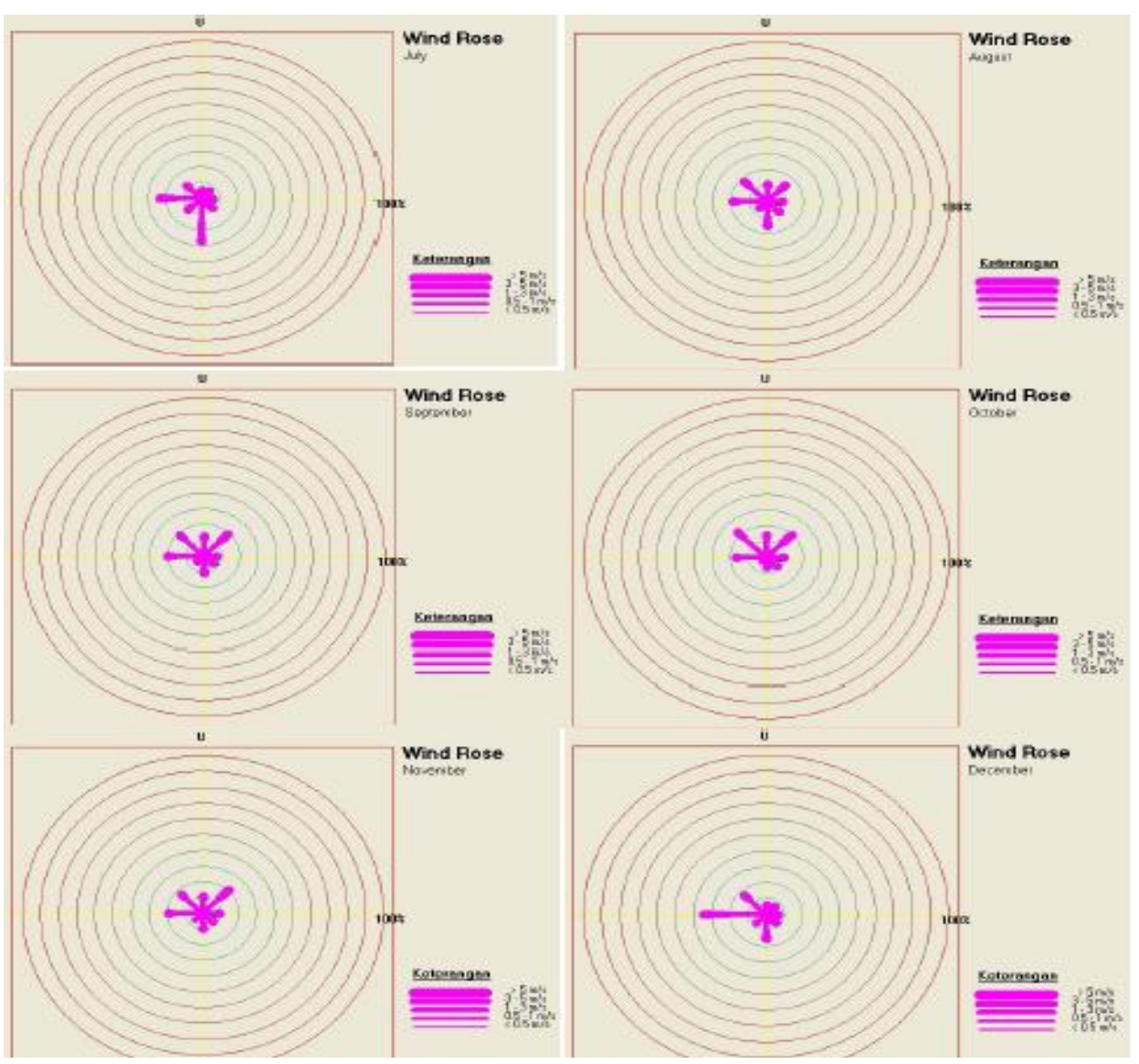

Gambar 3. Windrose data angin bulan Juli - Desember dari data tahun 2006 - 2010. 
Hasil simulasi tumpahan minyak dengan menggunakan software OilSpill pada bulan Januari sampai bulan Desember dapat dilihat pada Gambar 4 dan Gambar 5. Informasi yang dapat dilihat pada hasil simulasi adalah: yang memberikan informasi pola sebaran tumpahan minyak dan Waktu minimum yang diperlukan oleh minyak untuk menyebar dari sumber kejadian ke suatu lokasi tertentu biasa disebut dengan minimum drifting time (MDT).

Hasil simulasi ini menunjukkan adanya pola sebaran dan luas sebaran tumpahan minyak yang berbeda untuk bulan yang berbeda. Sebaran tumpahan minyak yang berasal dari perairan di sekitar Lhokseumawe menyebar sampai ke Pulau Weh pada bulan Januari, Pebruari, Juni, Juli, Agustus, September, Oktober, Nopember, dan Desember. Pada bulan Maret sebaran tumpahan minyak tersebut hanya mendekati Pulau Weh dan lewat disisi utaranya, sedangkan pada bulan April dan Mei tumpahan minyak yang berasal dari perairan di sekitar Lhokseumawe tidak pernah menyebar sampai ke Pulau Weh.

Minimum drifting time hasil simulasi tumpahan minyak dengan menggunakan software model OilSpill untuk bulan Januari sampai Desember dapat dilihat pada Gambar 4 dan Gambar 5. Informasi mengenai MDT sangat diperlukan untuk memperkirakan lama waktu yang dapat dimiliki dalam melakukan tindakan penyelamatan dan perlindungan terhadap lingkungan dan lokasi-lokasi vital apabila tumpahan minyak terjadi. Untuk kejadian tumpahan minyak yang terjadi di Lhokseumawe, MDT yang diperlukan oleh tumpahan minyak agar sampai ke perairan di sekitar Pulau Weh dapat digambarkan sebagai berikut:

- pada bulan Januari, MDT dari minyak yang tumpah sampai ke Pulau Weh diperkirakan antara $24-96$ jam,

- pada bulan Pebruari, MDT dari minyak yang tumpah sampai ke Pulau Weh diperkirakan antara $24-96$ jam,

- pada bulan Maret, sebaran minyak sebelum mencapai ke Pulau Weh dibelokkan ke arah utara sehingga tidak masuk ke wilayah perairan Puau We,

- pada bulan April, sebaran minyak lebh mengarah ke Utara sampai Timur sehingga tidak sampai masuk ke wilayah perairan Pulau Weh,

- pada bulan Mei, sebaran minyak lebih mengarah ke Utara sampai Timur sehingga tidak sampai masuk ke wilayah perairan Pulau Weh,

- pada bulan Juni, MDT dari minyak yang tumpah sampai ke Pulau Weh diperkirakan antara 96- 192 jam,
- pada bulan Juli, MDT dari minyak yang tumpah sampai ke Pulau Weh diperkirakan antara 96- 192 jam,

- pada bulan Agustus, MDT dari minyak yang tumpah sampai ke Pulau Weh diperkirakan antara $192-288$ jam,

- pada bulan September, MDT dari minyak yang tumpah sampai ke Pulau Weh diperkirakan antara 192 -288 jam,

- pada bulan Oktober, MDT dari minyak yang tumpah sampai ke Pulau Weh diperkirakan antara $192-288$ jam,

- pada bulan Nopember, MDT dari minyak yang tumpah sampai ke Pulau Weh diperkirakan antara 96- 192 jam, dan ,

- pada bulan Desember, MDT dari minyak yang tumpah sampai ke Pulau Weh diperkirakan antara 24 -96 jam.

Pulau Weh yang merupakan kawasan dengan keindahan alam laut yang tinggi merupakan pulau yang layak untuk dilindungi terhadap adanya sebaran tumpahan minyak di laut. Tercemarnya air laut oleh tumpahan minyak dapat menimbulkan gangguan pada kehidupan (flora dan fauna) yang ada di wilayah yang dilaluinya. Tumpahan minyak yang menyebar sampai ke Pulau Weh dapat berupa lapisan minyak atau partikel minyak yang sudah tercampur dengan air. Mengacu pada penelitian Fisher, et al. ${ }^{(10)}$, tumpahan minyak yang masuk ke taman laut nasional yang ada di sekitar Pulau Weh dapat mengganggu kehidupan terumbu karang di wilayah tersebut. Terganggunya kehidupan terumbu karang dapat mengakibatkan pada terjadinya pemutihan/kematian terumbu karang. Apabila hal ini terjadi maka ketertarikan wisatawan terhadap Pulau Weh menjadi berkurang. Berkurangnya ketertarikan wisatawan akan berakibat pada menurunnya jumlah wisatawan. Dengan menurunnya jumlah wisatawan yang tertarik datang ke Pulau Weh dapat mengakibatkan pada berkurangnya pendapatan ekonomi masyarakat dan pemerintah Kota Sabang. Hal ini sejalan dengan apa yang telah diteliti oleh Kusnandar ${ }^{(12)}$ tentang adanya keterkaitan antara terjadinya pencemaran dengan pendapatan masyarakat.

Tindakan pencegahan dan penanggulangan tumpahan minyak wajib dilakukan untuk menghindari terjadinya pencemaran terhadap daerah vital dan yang mempunyai nilai tinggi. Oleh karena itu, bagi setiap kegiatan yang berpotensi menimbulkan terjadinya tumpahan minyak wajib mempersiapkan tindakan dalam pencegahan dan penanggulangan tumpahan minyak. Tindakan yang dilakukan mencakup identifikasi keberadaan kapal khusus yang dilengkapi dengan peralatan pencegahan dan penanggulangan tumpahan minyak berada, 
jenis peralatan yang tersedia, metode yang digunakan, serta jumlah kapal dan peralatan yag tersedia. Hal ini perlu dilakukan untuk memastikan bahwa kegiatan yang dilakukan dapat memberi rasa aman buat pemerintah dan masyarakat yang berada di sekitar perairan dimana kegiatan tersebut dilakukan. Selain itu,

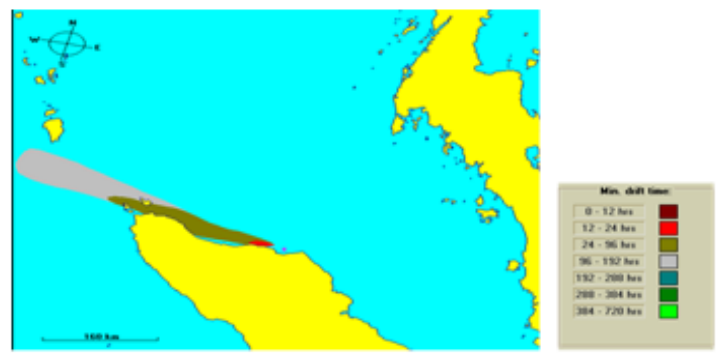

\section{Simulasi pada bulan Januari}

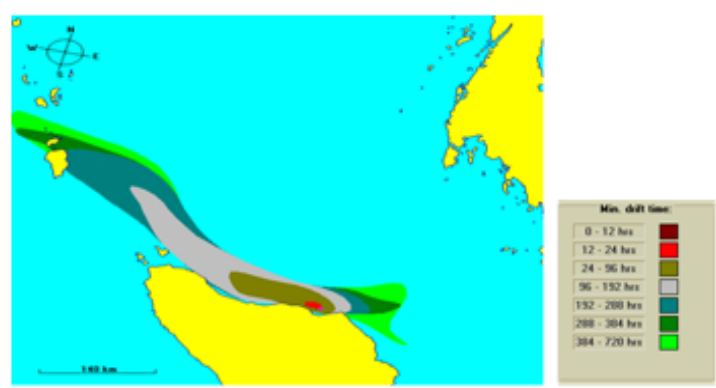

Simulasi pada bulan Maret
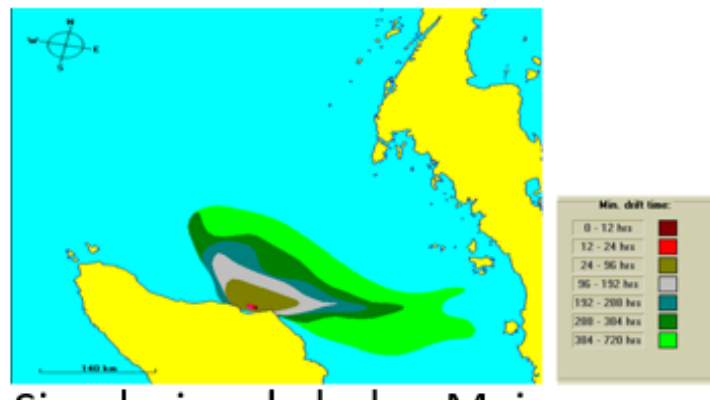

Simulasi pada bulan Mei tindakan pencegahan dan penanggulangan ini juga untuk menghindari terjadinya dampak negatif yang lebih buruk apabila tumpahan minyak terjadi dan menyebar ke kawasan strategis dan kawasan yang mempunyai nilai konservasi tinggi.

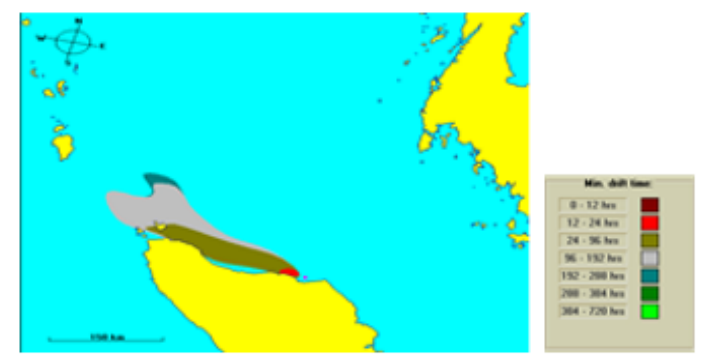

\section{Simulasi pada bulan Pebruari}
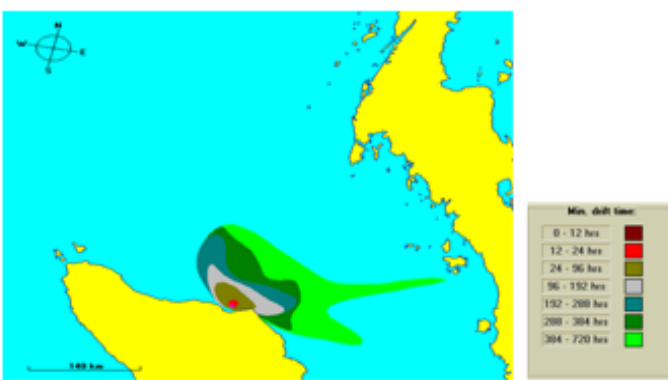

Simulasi pada bulan April

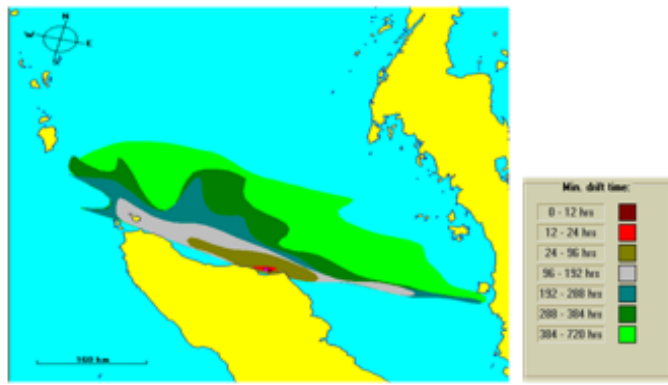

Simulasi pada bulan Juni

Gambar 4. Sebaran tumpahan minyak dan minimum drifting time dari hasil simulasi pada bulan Januari - Juni 


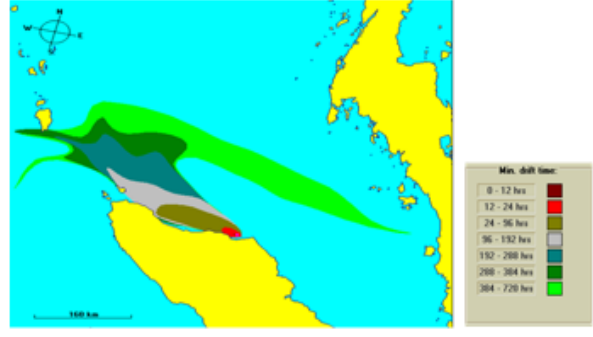

Simulasi pada bulan Juli

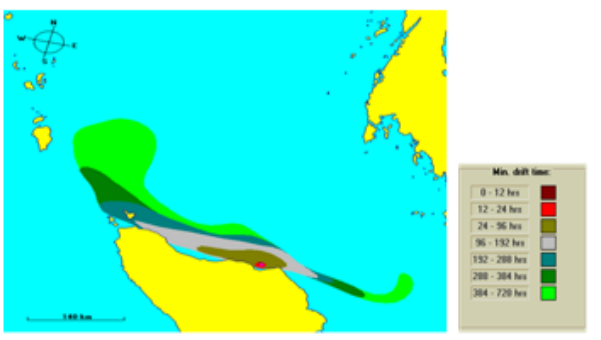

Simulasi pada bulan September

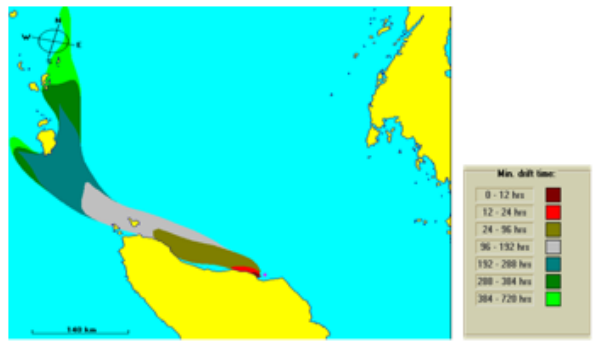

Simulasi pada bulan Nopember

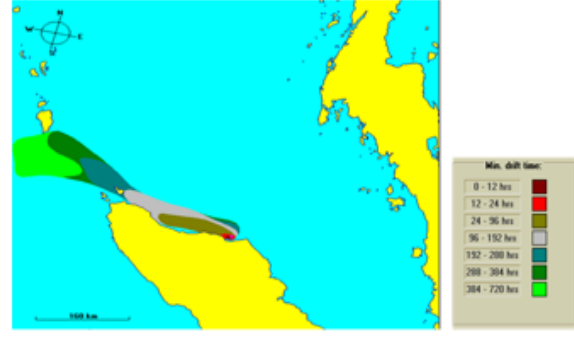

Simulasi pada bulan Agustus



Simulasi pada bulan Oktober

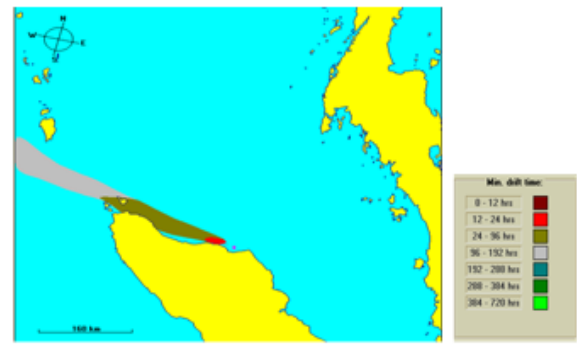

Simulasi pada bulan Desember

Gambar 5. Sebaran tumpahan minyak dan minimum drifting time dari hasil simulasi pada bulan Juli - Desember

Pengetahuan tentang MDT dapat digunakan sebagai acuan dalam membuat perencanaan aksi di dalam tindakan pencegahan dan penanggulangan tumpahan minyak. Minimum drifting time dapat digunakan sebagai bahan di dalam melakukan evaluasi dan manajemen pencegahan dan penanggulangan tumpahan minyak. Pengetahuan tentang MDT dapat digunakan untuk mengoptimalkan proses pencegahan dan penanggulangan tumpahan minyak. Pencegahan dan penanggulangan tumpahan minyak yang dilakukan secara dini dapat mengurangi resiko meluasnya sebaran tumpahan minyak. Pencegahan dan penanggulangan secara dini dapat mengurangi jumlah/volume minyak yang tumpah. Pencegahan dan penanggulangan tumpahan minyak akan efektif apabila dilakukan di lokasi yang dekat dengan sumber pencemaran terjadi. Dengan mengetahui MDT maka resiko kerusakan lingkungan akibat tumpahan minyak dapat dikurangi.

Efektifitas pencegahan

dan penanggulangan tumpahan minyak juga sangat tergantung pada jarak dimana ketersediaan peralatan pencegahan dan penanggulangan tersebut berada. Kecepatan proses pencegahan dan penanganan tumpahan minyak sangat tergantung lokasi kapal. Pada kasus tumpah minyak terjadi di perairan Lhokseumawe-NAD dan peralatan pencegahan dan penanggulangan tumpahan minyak terdapat di pelabuhan Belawan-Medan yang berjarak sekitar 319 atau maka kedatanagn kapal ke lokasi membutuhkan waktu sekitar 25,8 jam apabila kecepatan kapalnya 8 knot. Hal ini akan lebih lama lagi apabila ketersediaan kapal dan peralatan berada di Singapura yang jarak dari Lhokseumawe ke Singapura berjarak sekitar $897 \mathrm{~km}$ atau setara dengan 67 jam perjalanan kapal dengan kecepatan 8 knot. Semakin jauh lokasi kapal berada maka sebaran tumpahan minyak semakin melebar dan semakin sulit untuk diproteksi dan ditanggulangi.Semakin jauh keberadaan kapal berada maka waktu yang tersedia untuk melakukan tindakan pencegahan dan penanggulangan juga menjadi semakin sempit.

Berdasarkan hasil simulasi model pada Gambar 4 dan Gambar 5, apabila tumpahan 
minyak terjadi di bulan Januari, Pebruari atau Desember dan kapal khusus yang digunakan dalam pencegahan dan penangulangan tumpahan minyak didatangkan dari Medan terlebih lagi dari Singapura maka tumpahan minyak sudah tidak dapat dicegah untuk menyebar dan mencemari Pulau Weh (dengan kata lain sudah sangat terlambat). Apabila tumpahan minyak terjadi di bulan Juni atau September dan kapal didatangkan dari Medan maka masih ada sisa waktu 72 jam waktu tersisa untuk mencegah agar minyak yang tumpah tidak menyebar dan mencemari Pulau Weh, dan apabila kapal didatangkan dari Singapura maka hanya ada sekitar 30 jam waktu tersisa untuk mencegah minyak yang tumpah agar tidak menyebar dan mencemari Pulau Weh.

\section{KESIMPULAN}

Tumpahan minyak yang terjadi disekitar perairan Lhokseumawe pada bulan Januari, Pebruari, Juni, Juli, Agustus, September, Oktober, Nopember, dan Desember dapat menyebar ke Pulau Weh. Tumpahan minyak yang terjadi pada bulan Maret, sebarannya hanya mendekati Pulau Weh dan berbelok ke arah utara Pulau Weh. Tumpahan minyak yang terjadi pada bulan April dan Mei sebarannya tidak sampai ke Pulau Weh. Minimum drifting time (MDT) dari tumpahan minyak yang berasal dari perairan Lhokseumawe menuju Pulau Weh berkisar antara 24 jam - 288 jam yang tergantung pada kondisi angin dan arus pada bulan tersebut.

\section{PERSANTUNAN}

\begin{abstract}
Ucapan terimakasih saya sampaikan kepada Pusat Teknologi Lingkungan, khususnya kepada rekan-rekan yang pernah bergabung dalam Seawacth Indonesia atas perkenannya menggunakan software OilSpil for Windows version 3.0 .
\end{abstract}

\section{DAFTAR PUSTAKA.}

1. Mawardi, M.N, Syechalad, dan Syahnur, S. (2014). Faktor-Faktor yang Mempengaruhi Kunjungan Wisatawan ke Kota Sabang. Jurnal IImu Ekonomi. Pascasarjana Universitas Syiah Kuala. 2(4): 55-64

2. BPS. (2015). SUSENAS 2015

3. Shen, H.T. and P.D. Yapa, (1988). Oil Slick Transport in Rivers. J. Hydraulic Eng. 114: 529-543

4. Wang, S.D., Y.M. Shen, and Y.H. Zheng. (2005). Two-Dimensional Numerical Simulation for Transport and Fate of Oil
Spills in Seas. Ocean Engineering. Elsevier. 32: 1556-1571

5. Salim, A. dan T.E. Susanto, (2014). Model Pergerakan Tumpahan Minyak di Perairan Selat Sunda. CAUCHY. 3(2):99-107

6. Oceanor. (1996). OilSpil for Windows version 3.0, SEAWATCH Indonesia

7. Widhayanti, A., A., Ismanto, \& B. Yulianto, (2015). Sebaran Tumpahan Minyak Dengan Pendekatan Model Hidrodinamika dan Spill Analysis di Perairan Cilacap, Jawa Tengah. Jurnal Oseanografi. 4(4):641 - 650

8. Jimoh, A. \& M. Alhassan, (2006). Modelling and Simulation of Crude Oil Dispersion. Leonardo Electron. J. Pract. Technol. $5(8): 17-28$

9. Cho, Y.S., T.K. Kim, W. Jeong, and T. Ha,. (2012). Numerical Simulation of Oil Spill in Ocean. Journal of Applied Mathematics. 2012:1-15

10. Fisher, C.R., P.Y. Hsing, C.L Kaiser.., D.R Yoerger, H.H. Roberts,. W.W. Shedd, E.E. Cordes,. T.M. Shank, S.P. Berlet,., M.G. Saunders, E.A. Larcom, and J.M. Brooks, (2014). Footprint of Deepwater Horizon Blow Out Impact to Deep-Water Coral Communities. PNAS. 111(32): 1174411749

11. Lyons, R., J. Temple, D. Evans, D. L. Fone, and S. R. Palmer (1999). Acute Health Effects of The Sea Empress Oil Spill. Journal of Epidemiology and Community Health. 53:306-310.

12. Kusnandar, (2008). Valuasi Ekonomi Dampak Pencemaran Lingkungan Terhadap Kesejahteraan Masyarakat Pesisir di Kecamatan Medang Kampai Kota Dumai. Master Thesis. Sekolah Pascasarjana-IPB

13. Loureiro, M.L. (2014) Socio Economic and Environmental Impacts of the Prestige Oil Spill in Spain, Power Poin Presentation, University of Santiago de Compostela Spain

14. Suwedi, N. (2006). Teknologi Penanggulangan dan Pengendalian Kerusakan Lingkungan Pesisir, Pantai dan Laut untuk Mendukung Pengembangan Pariwisata, Jurnal Teknologi Lingkungan. 7(2):152-159

15. Anonim, (2010) Data Angin Stasiun Lhokseumave (2006-2010). - NAD. BMKG.

16. Suwedi, N. (2014). Petunjuk Penggunaan Software WindRose version 3.1 